\title{
Adaptation of mitochondrial ATP production in human skeletal muscle to endurance training and detraining
}

\author{
R. WIBOM, E. HULTMAN, M. JOHANSSON, K. MATHEREI, D. CONSTANTIN-TEODOSIU, \\ AND P. G. SCHANTZ \\ Departments of Clinical Chemistry II and Physiology III, Karolinska Institute, S-141 86 Huddinge; and \\ University College of Physical Education, S-114 86 Stockholm, Sweden
}

\begin{abstract}
Wibom, R., E. Hultman, M. Johansson, K. Matherei, D. Constantin-Teodosiu, and P. G. Schantz. Adaptation of mitochondrial ATP production in human skeletal muscle to endurance training and detraining. J. Appl. Physiol. 73(5): 20042010, 1992.- The adaptation of mitochondrial ATP production rate (MAPR) to training and detraining was evaluated in nine healthy men. Muscle samples $(\sim 60 \mathrm{mg})$ were obtained before and after 6 wk of endurance training and after 3 wk of detraining. MAPR was measured in isolated mitochondria by a bioluminometric method. In addition, the activities of mitochondrial and glycolytic enzymes were determined in skeletal muscle. In response to training, MAPR increased by $70 \%$, with a substrate combination of pyruvate + palmitoyl-L-carnitine $+\alpha$-ketoglutarate + malate, by $50 \%$ with only pyruvate + malate, and by $92 \%$ with palmitoyl-L-carnitine + malate. With detraining MAPR decreased by $12-28 \%$ from the posttraining rate (although not significantly for all substrates). No differences were found when MAPR was related to the protein content in the mitochondrial fraction. The largest increase in mitochondrial enzyme activities induced by training was observed for cytochrome-c oxidase (78\%), whereas succinate cytochrome $c$ reductase showed only an $18 \%$ increase. The activity of citrate synthase increased by $40 \%$ and of glutamate dehydrogenase by $45 \%$. Corresponding changes in maximal $\mathrm{O}_{2}$ uptake were a $9.6 \%$ increase by training and a $6.0 \%$ reversion after detraining. In conclusion, both MAPR and mitochondrial enzyme activities are shown to increase with endurance training and to decrease with detraining.
\end{abstract}

$\beta$-oxidation; carbohydrate metabolism; fat metabolism; luminescence; maximal oxygen uptake; oxidative enzymes; oxidative phosphorylation

SKELETAL MUSCLE is a remarkably plastic tissue that responds rapidly to increases and decreases in the degree of physical activity. Changes in metabolic capacity have been related to mitochondrial density (22), enzyme activities $(20,27)$, and rate of tissue $\mathrm{O}_{2}$ uptake $(13,20)$. The studies performed are in agreement that contractile activity and inactivity lead to increases and decreases, respectively, in all these forms of mitochondrial expression.

It has long been known that the maximal $\mathrm{O}_{2}$ uptake increases after training. This was shown to be associated with increases in mitochondrial enzymes in human muscle in the late 1960s and early 1970 s (for references see Ref. 27). Thus the activities of cytochrome-c oxidase and succinate dehydrogenase were found to be increased by training. However, no direct studies of mitochondrial res- piration in human muscle before and after training have been done.

The reason for this is that the classic method for measuring mitochondrial respiration (and ATP formation rate) requires the use of muscle of $\sim 0.5-1 \mathrm{~g}$ tissue obtained by surgical procedures $(7,14)$. This amount of tissue cannot easily be obtained repeatedly in healthy subjects. However, a sensitive bioluminometric method has recently been developed that permits mitochondrial ATP production rates (MAPR) to be determined by using different substrates $(36,37)$. The amount of tissue needed is $40-60 \mathrm{mg}$, a sample size that can be obtained repeatedly by the percutaneous needle biopsy technique described by Bergström (3). With this method it was recently shown that the MAPR was $\sim 80 \%$ higher in welltrained than in sedentary subjects (36).

Our aim in this study was to evaluate the response of MAPR to endurance training and subsequent detraining. At the same time we investigated several commonly used mitochondrial marker enzymes, thus enabling comparative analyses of these variables to be made.

\section{MATERIALS AND METHODS}

Subjects. Nine healthy untrained men [age $20 \pm 1$ (SD) yr, height $1.81 \pm 0.07 \mathrm{~m}$, and weight $74 \pm 5 \mathrm{~kg}$ ] volunteered for the study. The subjects were performing their military service, and all were carrying out duties of a sedentary character, such as office work or car driving. They had not done any regular physical training for the 3 mo immediately preceding this study. They all were fully informed about the purpose of the study and the risks and discomfort associated with the experiments before they volunteered to participate. The study was approved by the Ethics Committee of the Karolinska Institute.

Experimental protocol. The experiments were carried out during a 9 -wk period. In the first 6 wk the subjects underwent an endurance training program on a bicycle ergometer. This was immediately followed by a detraining period of $3 \mathrm{wk}$ without any physical activities other than those involved in everyday living. Submaximal and maximal work tests were performed, and muscle biopsy samples were taken before and after the training, as well as after the detraining.

Training protocol. The subjects trained, on the average, $4 \times 36 \mathrm{~min} / \mathrm{wk}$ for $6 \mathrm{wk}$ using bicycle ergometers (Monark, Varberg, Sweden or Cardionics, Stockholm, Swe- 
den). The absolute work load and the length of the training sessions were increased from $175 \pm 24 \mathrm{~W}$ and $30 \mathrm{~min} /$ day in week 1 to $200 \pm 30 \mathrm{~W}$ and $40 \mathrm{~min} /$ day in week 6 . The work load was adjusted so as to induce an $\mathrm{O}_{2}$ uptake corresponding to $70 \%$ of the maximal $\mathrm{O}_{2}$ uptake during the whole training period. This was achieved by monitoring each subject's heart rate (Sporttester PE 3000, Polar Electro, Kempele, Finland) during training and comparing it with the individual heart rate per $\mathrm{O}_{2}$ uptake relationship observed in laboratory experiments. The blood lactate levels (33) after 15 min of training were measured during weeks 2 and 6 and corresponded to $4.1 \pm 1.2$ and $4.6 \pm 1.9 \mathrm{mmol} / \mathrm{l}(n=7)$, respectively.

Submaximal and maximal cycle ergometer tests. The subjects were made familiar with the testing procedures on a separate occasion before the experiments were started. Before and after the training period, as well as after the detraining period, one maximal and two submaximal $(100 \mathrm{~W}, 150 \mathrm{~W})$ work loads were performed on a cycle ergometer (Monark) at $60 \mathrm{rpm} . \mathrm{O}_{2}$ uptake, heart rate, and lactate concentration in blood were determined for each work load.

$\mathrm{O}_{2}$ uptake was determined by the Douglas bag technique (1a), and the $\mathrm{O}_{2}$ and $\mathrm{CO}_{2}$ contents in the expired air were analyzed in a mass spectrometer (Centronic 200). Heart rate was measured with a pulse watch (Sporttester PE 3000). The blood lactate concentration was analyzed by a slight modification of Barker-Summerson's method (33). The linear relationship between $\mathrm{O}_{2}$ uptake and heart rate was determined for each subject at pretraining and was used to calculate the absolute work load during training.

Muscle biopsy sampling. The muscle biopsy samples were taken percutaneously under local anesthesia from the middle portion of the vastus lateralis, using a Bergström-Stille biopsy needle ( $6 \mathrm{~mm}$ diam) (3). The muscle samples, weighing $\sim 100 \mathrm{mg}$, were dissected free from visible fat and connective tissue on a glass plate cooled on ice. The samples were divided into four portions: two were used fresh [for determination of MAPR and succinate-cytochrome $c$ reductase (SCR) + NADH-cytochrome $c$ reductase (NCR), respectively; see below], and two were frozen in liquid nitrogen and stored at $-80^{\circ} \mathrm{C}$ for up to 3 mo for enzyme assays.

Determination of MAPR. The MAPR was determined by the bioluminescence technique, as originally described for rat skeletal muscle (37) and later applied to human skeletal muscle (36). Mitochondria were isolated from $\sim 60 \mathrm{mg}$ of fresh muscle by homogenization and subsequent differential centrifugation and were added to cuvettes containing $A D P, P_{i}$, substrates (see below), and firefly luciferase reagent (Bio Orbit Oy, Turku, Finland). This reagent emits a light proportional to the ATP concentration. MAPR was monitored at $25^{\circ} \mathrm{C}$ with the following substrate combinations: 1$)$ pyruvate $(1 \mathrm{mmol} / \mathrm{l})+$ L-malate $(1 \mathrm{mmol} / \mathrm{l})(\mathrm{P}+\mathrm{M}), 2)$ palmitoyl-L-carnitine $(0.005 \mathrm{mmol} / \mathrm{l})+\mathrm{L}$-malate $(1 \mathrm{mmol} / \mathrm{l})(\mathrm{PC}+\mathrm{M}), 3) \alpha$-ketoglutarate $(10 \mathrm{mmol} / \mathrm{l} ; \alpha-\mathrm{KG}), 4)$ succinate $(20 \mathrm{mmol} /$ l) + rotenone $(0.1 \mathrm{mmol} / \mathrm{l})(\mathrm{S}+\mathrm{R}), 5) N, N, N^{1}, N^{1}$-tetramethyl-1,4-phenyldiamine $(1 \mathrm{mmol} / \mathrm{l})+$ ascorbate $(5$ $\mathrm{mmol} / \mathrm{l})(\mathrm{T}+\mathrm{A})$, and 6$)$ pyruvate $(1 \mathrm{mmol} / \mathrm{l})+$ palmitoylL-carnitine $(0.005 \mathrm{mmol} / \mathrm{l})+\alpha-\mathrm{KG}(10 \mathrm{mmol} / \mathrm{l})+\mathrm{L}$-mal- ate $(1 \mathrm{mmol} / \mathrm{l})(\mathrm{PPKM})$. A cuvette containing mitochondria, but no added substrate, was used as a blank.

Calculations of MAPR. The MAPR was determined as millimoles ATP per minute per liter mitochondrial suspension. The intramitochondrial activity of glutamate dehydrogenase (GDH) was determined in the same suspension. Total GDH activity in the crude muscle homogenate was also determined (see below). The relative mitochondrial yield was calculated from the intramitochondrial GDH activity in the suspension and the GDH activity in the whole muscle, and with the use of this ratio the MAPR was referred to the muscle mass $\left(\mathrm{mmol} \cdot \mathrm{min}^{-1} \cdot \mathrm{kg}^{-1}\right)(36)$.

Protein. MAPR was also related to the content of alkali soluble protein in the mitochondrial suspension, as determined by the method of Lowry et al. (24).

Enzyme assays: SCR (EC 1.3.99.1) and NCR (EC 1.6.99.3). Fresh muscle ( $\sim 15 \mathrm{mg}$ wet wt) was homogenized in a Potter-Elvehjem homogenizer (1:50 wt/vol) in a solution consisting of (in mmol/l) $100 \mathrm{KCl}, 50$ tris(hydroxymethyl)aminomethane, $5 \mathrm{MgCl}_{2}, 1.8 \mathrm{ATP}$, and 1 EDTA, $\mathrm{pH}$ 7.2. SCR was spectrophotometrically determined at $25^{\circ} \mathrm{C}$ by the method of Cooperstein et al. (11). NCR was essentially determined as SCR, but the reaction was started with NADH $(0.5 \mathrm{mmol} / \mathrm{l})$ instead of succinate. The extinction coefficient of cytochrome $c$ was taken as $21.1 \mathrm{l} \cdot \mathrm{mmol}^{-1} \cdot \mathrm{cm}^{-1}(550 \mathrm{~nm})$.

$G D H$ (EC 1.4.1.4). Pieces of frozen muscle ( $\sim 5 \mathrm{mg}$ wet wt) were thawed and homogenized in a Potter Elvehjem homogenizer. In the mitochondrial suspension the GDH activity was determined with and without the disruption of intact mitochondria, and the intramitochondrial GDH activity was calculated. The extramitochondrial fraction arises from mitochondria disrupted during the preparation of mitochondria. The procedures were described in detail in Ref. 36. The GDH activity was analyzed spectrophotometrically at $35^{\circ} \mathrm{C}(31)$.

For the remaining enzymes a frozen muscle sample ( $\sim 20 \mathrm{mg}$ wet wt) was thawed and homogenized (1:25 wt/ vol) in a Potter Elvehjem homogenizer containing icecold potassium phosphate buffer $(0.3 \mathrm{~mol} / \mathrm{l})$ and bovine serum albumin $(0.05 \%$, wt/vol $), \mathrm{pH} 7.7$. The homogenate was stored at $-80^{\circ} \mathrm{C}$ for subsequent analyses of the following enzymes.

6-Phosphofructokinase (PFK, EC 2.7.1.11), $\beta$-hydroxyacyl-CoA dehydrogenase (HAD, EC 1.1.1.35), and citrate synthase (CS, EC 4.1.3.7). PFK, HAD, and CS were determined spectrophotometrically at $25^{\circ} \mathrm{C}$, as described by Opie and Newsholme (26), Bass et al. (2), and Alp et al. (1), respectively.

Malate dehydrogenase ( $M D H, E C$ 1.1.1.37). $\mathrm{MDH}$ was determined spectrophotometrically at $25^{\circ} \mathrm{C}$ by the method of Bücher et al. (5). The cytoplasmic and mitochondrial isoenzymes of $\mathrm{MDH}$ (cMDH, mMDH, respectively) were assayed as described in detail by Schantz (28).

Cytochrome-c oxidase (COX, EC 1.9.3.1). COX was determined polarographically at $30^{\circ} \mathrm{C}$ by the method of Tottmar et al. (34).

Statistical analyses. All statistical calculations were based on one-way analysis of variance (ANOVA). Differences were determined with Scheffé's test, and $P<0.05$ 
TABLE 1. Heart rate, lactate concentration in blood, and maximal $\mathrm{O}_{2}$ uptake determined at different work loads before and after training and after detraining

\begin{tabular}{lcccc}
\hline \hline & & $\begin{array}{c}\text { Before } \\
\text { Training }\end{array}$ & $\begin{array}{c}\text { After } \\
\text { Training }\end{array}$ & $\begin{array}{c}\text { After } \\
\text { Detraining }\end{array}$ \\
\hline Heart rate, beats/min & $100 \mathrm{~W}$ & $125 \pm 7$ & $121 \pm 6$ & $120 \pm 7$ \\
& $150 \mathrm{~W}$ & $147 \pm 6$ & $141 \pm 8^{*}$ & $140 \pm 7 \ddagger$ \\
& $\mathrm{Max}$ & $187 \pm 10$ & $190 \pm 10$ & $188 \pm 11$ \\
Lactate concn in blood, & & & & \\
mmol/l & $100 \mathrm{~W}$ & $2.5 \pm 1.3$ & $1.9 \pm 0.3$ & $1.6 \pm 0.4$ \\
& $150 \mathrm{~W}$ & $3.7 \pm 1.5$ & $2.5 \pm 0.9^{*}$ & $2.5 \pm 1.2 \ddagger$ \\
& $\mathrm{Max}$ & $10.9 \pm 2.0$ & $12.6 \pm 2.2$ & $11.4 \pm 2.8$ \\
$\begin{array}{l}\text { Maximal } \\
\text { l/min }\end{array}$ & $\mathrm{Max}$ & $3.29 \pm 0.37$ & $3.61 \pm 0.40^{*}$ & $3.37 \pm 0.34 \dagger$ \\
\hline
\end{tabular}

Values are means $\pm \mathrm{SD} ; n=9$ men. Max, maximal work load. Significant differences with ANOVA $(P<0.05)$ between * before and after training, $\uparrow$ after training and after detraining, and $\ddagger$ before training and after detraining.

was considered significant. Results are presented as means $\pm \mathrm{SD}$.

\section{RESULTS}

Posttraining and detraining values are described here in terms relating to pretraining levels. Only significant differences are given here. Relative changes with detraining were calculated from the posttraining value.

Physiological responses to training and detraining. The responses in heart rate and blood lactate concentration to submaximal and maximal work loads, as well as the maximal $\mathrm{O}_{2}$ uptake, are given in Table 1 . The pretraining maximal $\mathrm{O}_{2}$ uptake was $44 \pm 4 \mathrm{ml} \cdot \mathrm{kg}^{-1} \cdot \mathrm{min}^{-1}$. The $6 \mathrm{wk}$ of endurance training and subsequent 3 wk of detraining resulted in an increase $(9.6 \pm 2.3 \%)$ and decrease $(6.0 \pm$ $6.7 \%$ ), respectively, in the maximal $\mathrm{O}_{2}$ uptake, expressed as liters per minute. Training resulted in a significantly lower heart rate and blood lactate concentration in response to the higher of the two submaximal work loads, changes that were not reversed by the detraining ( $\mathrm{Ta}$ ble 1).

Mitochondrial yield. The protein yield of the mitochondrial suspension (determined as $\mathrm{g}$ protein isolated $/ \mathrm{kg}$ muscle homogenized) was $3.90 \pm 0.64$ and $6.88 \pm 1.20$ $\mathrm{g} / \mathrm{kg}(n=9)$ before and after training, respectively, and corresponded to an average increase of $80 \pm 39 \%$. After detraining the protein yield was $5.60 \pm 1.25 \mathrm{~g} / \mathrm{kg}(n=8)$, which was $46 \pm 35 \%$ above the pretraining level.

The efficiency of the isolation procedure of mitochondria was determined as the percent intramitochondrial GDH activity in the mitochondrial suspension obtained from total muscle GDH activity. It was $26 \pm 7,27 \pm 3$, and $26 \pm 4 \%$ in the samples obtained before and after training and after detraining, respectively. No significant differences were found.

MAPR in muscle. With training the MAPR, expressed in millimoles per minute per kilogram muscle, increased significantly in all the substrates tested (Table 2). For the substrate combination PPKM, the single substrates $\alpha-\mathrm{KG}$ and $\mathrm{S}+\mathrm{R}$, and the artificial substrate $\mathrm{T}+\mathrm{A}$, the increases were similar and varied between $66 \pm 35$ and $70 \pm 32 \%$. The activity of the substrate $\mathrm{PC}+\mathrm{M}$ showed the highest increase, $92 \pm 58 \%$, which was significantly
TABLE 2. Mitochondrial ATP production rates before and after detraining

\begin{tabular}{lccr}
\hline \hline Substrate & $\begin{array}{c}\text { Before } \\
\text { Training }\end{array}$ & $\begin{array}{c}\text { After } \\
\text { Training }\end{array}$ & $\begin{array}{c}\text { After } \\
\text { Detraining }\end{array}$ \\
\hline PPKM & $7.5 \pm 1.6$ & $12.4 \pm 1.4^{*}$ & $10.2 \pm 1.1 \dagger+$ \\
$\mathrm{T}+\mathrm{A}$ & $6.4 \pm 1.5$ & $10.5 \pm 1.0^{*}$ & $8.5 \pm 1.3 \dagger+$ \\
$\alpha-\mathrm{KG}$ & $4.8 \pm 1.1$ & $7.9 \pm 1.0^{*}$ & $6.5 \pm 0.8 \dagger+$ \\
$\mathrm{PC}+\mathrm{M}$ & $2.43 \pm 0.86$ & $4.27 \pm 0.59^{*}$ & $3.74 \pm 0.63 \dagger$ \\
$\mathrm{P}+\mathrm{M}$ & $2.24 \pm 0.68$ & $3.20 \pm 0.63^{*}$ & $2.40 \pm 0.40 \dagger$ \\
$\mathrm{S}+\mathrm{R}$ & $2.39 \pm 0.53$ & $3.84 \pm 0.57^{*}$ & $2.70 \pm 0.30 \dagger$ \\
\hline
\end{tabular}

Values are means $\pm \mathrm{SD}$, are related to muscle mass, and are in mmol ATP $\cdot \min ^{-1} \cdot \mathrm{kg} \mathrm{muscle}^{-1}\left(25^{\circ} \mathrm{C}\right) ; n=9$ men. PPKM, pyruvate + palmitoyl-L-carnitine $+\alpha$-ketoglutarate + malate; $\mathrm{T}+\mathrm{A}, N, N, N^{1}, N^{1}$-tetramethyl-1,4-phenyldiamine + ascorbate; $\alpha$-KG, $\alpha$-ketoglutarate; $\mathrm{PC}+\mathrm{M}$, palmitoyl-L-carnitine + malate; $\mathrm{P}+\mathrm{M}$, pyruvate + malate; $\mathrm{S}+\mathrm{R}$, succinate + rotenone. Significant differences with ANOVA $(P<$ 0.05 ) between ${ }^{*}$ before and after training, $\dagger$ after training and after detraining, and $\ddagger$ before training and after detraining.

TABLE 3. Mitochondrial ATP production rates before and after training and after detraining

\begin{tabular}{lccc}
\hline \hline Substrate & $\begin{array}{c}\text { Before } \\
\text { Training }\end{array}$ & $\begin{array}{c}\text { After } \\
\text { Training }\end{array}$ & $\begin{array}{c}\text { After } \\
\text { Detraining }\end{array}$ \\
\hline PPKM & $0.48 \pm 0.06$ & $0.50 \pm 0.18$ & $0.51 \pm 0.15$ \\
T+A & $0.41 \pm 0.05$ & $0.42 \pm 0.09$ & $0.40 \pm 0.14$ \\
$\alpha-\mathrm{KG}$ & $0.30 \pm 0.04$ & $0.32 \pm 0.08$ & $0.33 \pm 0.10$ \\
PC+M & $0.15 \pm 0.03$ & $0.18 \pm 0.05$ & $0.19 \pm 0.07$ \\
P+M & $0.14 \pm 0.03$ & $0.13 \pm 0.03$ & $0.12 \pm 0.04$ \\
S+R & $0.15 \pm 0.01$ & $0.16 \pm 0.04$ & $0.13 \pm 0.04$ \\
\hline
\end{tabular}

Values are means $\pm \mathrm{SD}$, are related to protein content in mitochondrial suspension, and are in $\mathrm{mmol} \mathrm{ATP} \cdot \min ^{-1} \cdot g$ protein ${ }^{-1}\left(25^{\circ} \mathrm{C}\right) ; n=$ 8 men. No significant differences were found with ANOVA.

different from the increase in $\mathrm{P}+\mathrm{M}, 50 \pm 36 \%(P<$ $0.001)$. No other differences in increases were found between the substrates. Malate is added to the reaction mixtures to maintain a high intramitochondrial concentration of this substance, which enables the tricarboxylic acid cycle to function. After detraining, the MAPR of the substrates PPKM, T+A, and S+R decreased significantly $(17 \pm 16 \%$ to $28 \pm 16 \%)$ compared with after training. After detraining, the MAPRs were still higher than the pretraining level for the following substrates: PPKM, $40 \pm 35 \% ; \mathrm{T}+\mathrm{A}, 37 \pm 32 \% ; \alpha-\mathrm{KG}, 41 \pm 46 \%$; and $\mathrm{PC}+\mathrm{M}$, $70 \pm 54 \%$.

The MAPRs were also related to the protein content in the mitochondrial suspension (Table 3). No significant differences were found between the untrained, trained, and detrained conditions when the mitochondrial protein was used as the reference base.

Enzyme activities in muscle. The enzyme activities before and after training and after detraining are presented in Table 4. Enzyme activities of $\mathrm{cMDH}$ and PFK were not changed by training and detraining, except for a $16 \pm$ $8 \%$ increase in PFK after detraining. As expected, the training-induced increases in the activities of $\mathrm{mMDH}$, $\mathrm{CS}$, and GDH were $28 \pm 28,43 \pm 36$, and $47 \pm 25 \%$, respectively. After detraining, the activities were still $33 \pm 40$ and $30 \pm 32 \%$ above the pretraining levels for CS and GDH but not for mMDH. No significant changes were seen in the activity of HAD.

The training-induced increases in activities of the 
TABLE 4. Enzyme activities in muscle before and after 6 wk training and after $3 w k$ detraining

\begin{tabular}{lccc}
\hline \hline Enzymes & $\begin{array}{c}\text { Before } \\
\text { Training }\end{array}$ & $\begin{array}{c}\text { After } \\
\text { Training }\end{array}$ & $\begin{array}{c}\text { After } \\
\text { Detraining }\end{array}$ \\
\hline PFK & $36.7 \pm 3.2$ & $34.2 \pm 7.6$ & $40.1 \pm 5.6 \dagger \ddagger$ \\
cMDH & $161 \pm 25$ & $149 \pm 37$ & $168 \pm 34$ \\
mMDH & $80 \pm 14$ & $95 \pm 22^{*}$ & $85 \pm 15$ \\
HAD & $16.9 \pm 3.0$ & $20.0 \pm 3.3$ & $18.0 \pm 3.2$ \\
CS & $13.0 \pm 2.7$ & $18.1 \pm 3.3^{*}$ & $16.4 \pm 1.8 \ddagger$ \\
GDH & $1.33 \pm 0.17$ & $1.94 \pm 0.24^{*}$ & $1.69 \pm 0.22 \ddagger$ \\
NCR & $5.6 \pm 1.6$ & $7.8 \pm 1.5^{*}$ & $7.3 \pm 1.6$ \\
SCR & $2.46 \pm 0.34$ & $2.91 \pm 0.24^{*}$ & $2.67 \pm 0.38$ \\
COX & $1.84 \pm 0.27$ & $3.15 \pm 0.46^{*}$ & $2.71 \pm 0.60 \ddagger$ \\
\hline
\end{tabular}

Values are means $\pm \mathrm{SD}$ in $\mathrm{mmol} \cdot \mathrm{min}^{-1} \cdot \mathrm{kg}$ muscle ${ }^{-1} ; n=9$ men (except for NCR, SCR, and COX, where $n=8$ men). PFK, phosphofructokinase; $\mathrm{cMDH}, \mathrm{mMDH}$, cytoplasmic and mitochondrial isoenzymes of malate dehydrogenase, respectively; $\mathrm{HAD}, \beta$-hydroxyacylCoA dehydrogenase; $\mathrm{CS}$, citrate synthase; $\mathrm{GDH}$, glutamate dehydrogenase; NCR, SCR, NADH and succinate cytochrome $c$ reductase, respectively; COX, cytochrome- $c$ oxidase. Significant differences with ANOVA $(P<0.05)$ between * before and after training, $\dagger$ after training and after detraining, and $\ddagger$ before training and after detraining.

membrane-bound enzyme complexes varied from $21 \pm$ $21 \%$ for SCR and $48 \pm 47 \%$ for NCR up to $78 \pm 36 \%$ for COX. No significant changes occurred with detraining. However, after detraining, only the COX activity was significantly higher $(50 \pm 39 \%)$ than the pretraining level.

Comparison between changes in enzyme activities and $M A P R$. Several of the enzymes included in this study are used as markers for different mitochondrial processes. It is therefore of interest to estimate to what extent changes in enzyme activities reflect changes in MAPR.

The substrates used to measure MAPR were PPKM, representing a combination of fat and carbohydrate utilization, $\mathrm{PC}+\mathrm{M}$ representing fat oxidation, and the artificial substrate $\mathrm{T}+\mathrm{A}$ measuring the activity of complex IV (COX) + complex V.

The training-induced activity changes in the mitochondrial enzymes GDH $(51 \pm 21 \%)$, CS $(46 \pm 38 \%)$, SCR $(21 \pm 21 \%)$, and COX $(76 \pm 38 \%, n=8)$ were compared with the changes in MAPR with the substrate PPKM (72 $\pm 33 \%$; Fig. 1$)$. Of these, only the change in SCR was significantly lower than that in MAPR. A significant difference was also found when the $\beta$-oxidation enzyme HAD $(22 \pm 31 \%)$ was compared with MAPR with $\mathrm{PC}+\mathrm{M}(92 \pm 58 \%)$, whereas the change in COX (78 \pm $36 \%, n=9)$ closely resembled MAPR with $\mathrm{T}+\mathrm{A}(70 \pm$ $39 \%$; Fig. 1).

Corresponding comparisons were made regarding the decreases induced by detraining. These changes were smaller (range 4-17\%), and no significant differences between changes in MAPR and in enzyme activities were found. The parameters investigated showed relatively large variations. To some extent, this can be explained by the lack of homogeneity in the muscle tissue analyzed. For example, the coefficient of variation in MAPR was found to be $10 \%$ in two samples from the same leg (36). A corresponding coefficient of variation $(8-10 \%)$ has been noted for enzyme activities (16).

Another cause of the variation in changes between MAPR and enzyme activities can be due to the muscle mitochondria having different localizations within the cell. Two subpopulations have been described, subsarcolemmal and intermyofibrillar mitochondria (14). The proportion of these subpopulations in the purified mitochondrial fractions presently studied is not known. The adaptive pattern of these subpopulations could differ and would in such case introduce a variability in the comparison between whole muscle measurements of enzyme activities and MAPR.

\section{DISCUSSION}

In the present study a 6 -wk endurance training program was followed by $3 \mathrm{wk}$ of detraining. Classic effects of physical training were seen, e.g., increased maximal $\mathrm{O}_{2}$ uptake and decreased heart rate and blood lactate levels at submaximal work (1a). An increase of $9 \%$ and a decrease of $6 \%$ in maximal $\mathrm{O}_{2}$ uptake was found in response to the training and detraining, respectively. Furthermore, the well-known pattern of changes in oxidative enzymes induced by physical activity and inactivity was essentially reproduced $(18,29)$. All these findings are in accord with previous training and detraining studies, and the intended effects of the training were thus attained.

In the present investigation mitochondria were isolated from muscle samples obtained by a percutaneous needle biopsy technique. The weight of the samples was $\sim 60 \mathrm{mg}$. After the 6-wk training period the mitochondrial fraction had increased by $\sim 80 \%$, measured as protein content in the suspension. After the detraining period, the content was $46 \%$ higher than the pretraining content. The efficiency of the isolation procedure (measured as the intramitochondrial GDH activity in the mitochondrial suspension compared with that in the muscle sample) was constant: on the average it was $26-27 \%$ on the three measurement occasions. The changes in mitochondrial protein (although the decrease with detraining was not significant) were matched by similar changes in MAPR with the different substrate combinations, indicating that the MAPR, expressed per gram mitochondrial protein, was unchanged (see Table 3).

These findings are in conformity with studies in animals. Holloszy (20) and Davies et al. (13) reported 60$70 \%$ increases in mitochondrial protein with physical training of rats. Such changes were directly related to increases in mitochondrial respiration, and thus the respiration, expressed per unit of mitochondrial protein, was unchanged.

The present results bear out the observation in a previous cross-sectional study where a group of physically highly active subjects (mainly elite ice-hockey players) showed a $67 \%$ higher MAPR with PPKM than a group of sedentary subjects (36). The $70 \%$ increase in the corresponding MAPR is remarkable in light of the short training period $(6 \mathrm{wk})$. The subjects reached a rate of 12.4 $\mathrm{mmol} \mathrm{ATP} \cdot \mathrm{min}^{-1} \cdot \mathrm{kg}^{-1}$ after training, which is comparable to the level of $11.0 \mathrm{mmol} \mathrm{ATP} \cdot \mathrm{min}^{-1} \cdot \mathrm{kg}^{-1}$ for the highly active group in the previous study (36).

An increased contribution of fat to the energy metabolism during submaximal work in response to endurance training has been shown $(9,17,19)$. The mechanism for this is not clear, but it has been viewed as a result of the total increase in mitochondrial density as such $(15,21)$. 

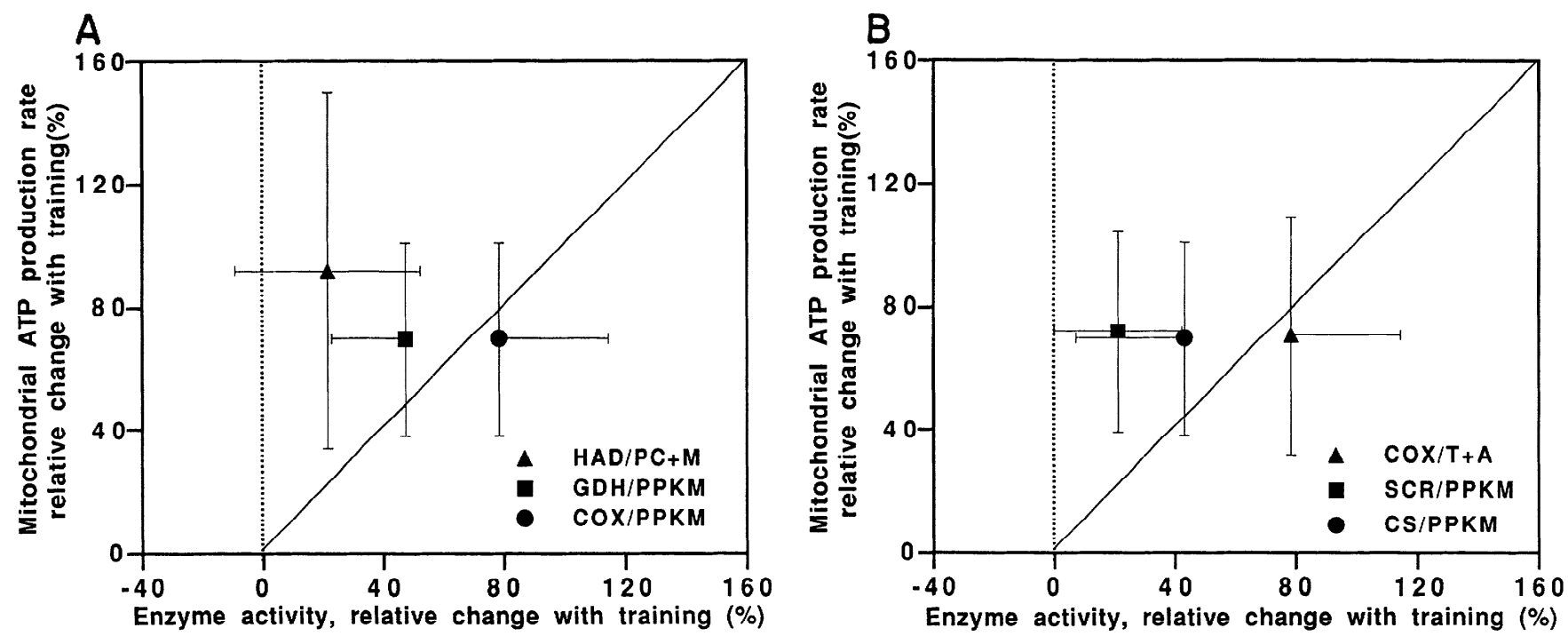

FIG. 1. Relationships between changes in mitochondrial enzyme activities and mitochondrial ATP production rates in response to training (relative to the pretraining level). Data are means $\pm \mathrm{SD}$. A: relationships between changes in enzyme activities of $\beta$-hydroxyacyl-CoA dehydrogenase (HAD), glutamate dehydrogenase (GDH), and cytochrome-c oxidase (COX) to an increased ATP production rate from palmitoyl-L-carnitine + malate $(\mathrm{PC}+\mathrm{M})$ and pyruvate + palmitoyl-L-carnitine $+\alpha$-ketoglutarate + malate (PPKM). $B$ : corresponding relationships for enzymes citrate synthase (CS), succinate cytochrome $c$ reductase (SCR), and COX to substrates PPKM and $N, N, N^{1}, N^{1}$-tetramethyl-1,4phenyldiamine + ascorbate $(\mathrm{T}+\mathrm{A})$.

An increase in the mitochondrial density would lead to an enhanced muscle capacity to phosphorylate ADP, which would reduce the ADP content in muscle during submaximal exercise. The effect of the lower level of ADP and secondarily AMP would also give a lower stimulation of glycolysis at the trained state. The contribution of fat to the energy metabolism during exercise would thereby automatically increase, even without a change in the mitochondrial composition (15). However, specific changes in various mitochondrial functions induced by training cannot be excluded.

Of interest are the present results showing that the largest increase in MAPR occurred with the substrate $\mathrm{PC}+\mathrm{M}(92 \%)$. The substrate $\mathrm{P}+\mathrm{M}$ gave a lower increase $(50 \%)$. Similar results have been obtained in a study of rats where the oxidation rate of $\mathrm{PC}+\mathrm{M}$ in homogenates of whole muscle was increased by $127 \%$ in the endurance-trained group compared with the untrained group, whereas the corresponding value for $\mathrm{P}+\mathrm{M}$ was $67 \%$ (13). In the same report it was calculated that the contribution of lipid oxidation during exercise was three times higher in a group of trained than in a group of untrained rats. The difference in increase of MAPR between the two substrates is surprising as the catalytic product in the mitochondria for both substrates is acetyl-CoA. The difference would consequently depend on the rate of acetylCoA formation from the two substrates, being less increased from pyruvate than from palmitoyl-L-carnitine. In a training study of rats, Molé et al. (25) found $100 \%$ increases of the activity of the enzymes palmitoyl-CoA synthetase, carnitine palmitoyl-transferase, and palmitoyl-CoA dehydrogenase. This would give a similar increase of the capacity to form acetyl-CoA from palmitoyl-L-carnitine. The rate of pyruvate utilization is dependent on the pyruvate uptake by the mitochondria and the activity of pyruvate dehydrogenase (PDH). The
$\mathrm{PDH}$ activity is low in resting muscle, and only a few studies on the effect of training have been performed. Thus a training study of rats showed a $70 \%$ increase of the active form of PDH in resting muscle but no increase of total PDH (4). Similar changes were observed in human muscle by Ward et al. (35).

In a recent study by Constantin-Teodosiu et al. (10) it was shown that exercise with submaximal work loads increased the PDH activity (the active form) by four to five times, with a similar increase of acetyl-CoA formation from pyruvate. The effect of exercise on the availability of acetyl-CoA from pyruvate should be taken into account when pyruvate oxidation in exercising humans is compared with values observed in mitochondrial suspensions obtained from resting muscle. The relationship between carbohydrate and fat utilization in exercising muscle can consequently not be established from in vitro studies of oxidative capacities. However, the large increase in the capacity of isolated mitochondria to produce ATP from fat could have an impact on fat utilization during exercise after training.

Analyses of marker enzyme activities for estimating the training-induced increases in the MAPR have frequently been used. On the basis of average values it appears from this study that GDH, COX, and CS are suitable marker enzymes, whereas SCR and HAD are poor mitochondrial markers. The smaller training-induced increase in HAD than in other mitochondrial enzymes has been observed previously $(6,29,30)$, and the striking difference between changes in HAD activity and the rate of ATP production from palmitoyl-L-carnitine further indicate that HAD activity also does not accurately reflect the mitochondrial capacity for fat utilization.

The activities of mMDH and NCR were not compared with the MAPR because mMDH is a component in the malate-aspartate shuttle and therefore also depends on 
cytosolic factors, and the method for NCR determination used in the present study was not specific for the mitochondrial enzyme activity (32).

To our knowledge no other studies have been presented concerning the effects of detraining on $\mathrm{O}_{2}$ consumption or the ATP production rate by isolated mitochondria. In the present study a decline was observed in the MAPR of all substrates (12-28\%) over a 3-wk period of detraining, although it was not significant in some cases. Costill et al. (12) measured the respiratory capacity, with pyruvate as the substrate, in crude homogenates of biopsy samples from the posterior deltoid muscle of swimmers during detraining. Even during the 1 st wk of detraining they noted a $50 \%$ decline, but no other changes occurred during the subsequent 3 wk. The decline was larger than in the present study, which may be related to the fact that Costill et al. studied a nonpostural muscle, whereas we studied a postural muscle.

The decreases in MAPR with detraining were paralleled by decreases in mitochondrial enzyme activities, as reported previously $(8,18,29)$. The rates of retrogression varied, however, between the different studies. For example, Henriksson and Reitman (18) found that the COX activity had returned to the pretraining level 2 wk after the cessation of training, whereas both the present results and those of Klausen et al. (23) indicate a slower rate of retrogression.

In conclusion, this study further extends our knowledge of the adaptability of the mitochondrial function in human skeletal muscle. For the first time it is shown that the MAPR in human muscles increases with physical training and decreases with detraining. This is matched in all essentials by changes in mitochondrial enzyme activities. The largest increase in the MAPR after training was observed when $\mathrm{PC}+\mathrm{M}$ was used as the substrate.

We thank the volunteers and the obliging staff at the Berga Naval School. The capable technical assistance of A.-M. Forsberg, L. Karlsson, E. Nilsson, S. Nordström, L. Rydén, B. Sjöberg, and H. Åhlman is gratefully acknowledged.

This work was supported by Swedish Medical Research Council Grant 02647; Swedish Sports Research Council Grants 75/85, 68/86, $86 / 87$, and 64/89; and research funds of the Karolinska Institute.

Address for reprint requests: R. Wibom, Dept. of Clinical Chemistry I; C2:72, Huddinge University Hospital, S-141 86 Huddinge, Sweden.

Received 23 September 1991; accepted in final form 1 June 1992.

\section{REFERENCES}

1. Alp, P., E. Newsholme, AND V. Zammit. Activities of citrate synthase and $\mathrm{NAD}^{+}$-linked and $\mathrm{NADP}^{+}$-linked isocitrate dehydrogenase in muscle from vertebrates and invertebrates. Biochem. J. 154: 689-700, 1976 .

1a.Åstrand, P.-O., AND K. RoDahL. Textbook of Work Physiology (3rd ed.). New York: McGraw-Hill, 1986.

2. Bass, A., D. BrdiczKa, P. Eyer, S. Hofer, and D. PetTe. Metabolic differentiation of distinct muscle types at the level of enzymatic organization. Eur. J. Biochem. 10: 198-206, 1969.

3. BergströM, J. Muscle electrolytes in man. Determination by neutron activation analysis on needle biopsy specimens. A study on normal subjects, kidney patients and patients with chronic diarrhoea. Scand. J. Clin. Lab. Invest. 14, Suppl. 68: 1-110, 1962.

4. Brozinick, J. T., JR., V. K. PATel, AND G. L. DohM. Effects of fasting and training on pyruvate dehydrogenase activation during exercise. Int. J. Biochem. 20: 297-301, 1988.

5. BÜCHER, T., W. LUH, AND D. PETTE. Einfache und zusammenge- setzte optische Tests mit Pyridin nucleotiden. In: Handbuch der Physiologisch- und Patologisch-Chemischen Analyse, edited by F. Hoppe-Seyler and H. Thierfelder. Berlin: Springer-Verlag, 1964, vol. 6, pt. A, p. 307.

6. Bylund, A.-C., T. Bjurö, G. Cederblad, J. Holm, K. Lundholm, M. SJöström, K. A. Ängquist, AND T. Scherstén. Physical training in man. Skeletal muscle metabolism in relation to muscle morphology and running ability. Eur. J. Appl. Physiol. Occup. Physiol. 36: 151-169, 1977.

7. BYRne, E., AND I. TROUNCE. Oxygen electrode studies with human skeletal muscle mitochondria in vitro. J. Neurol. Sci. 69: 319-333, 1985.

8. ChI, M. M.-Y., C. S. Hintz, E. F. Coyle, W. H. Martin III, J. L. IVy, P. M. NEMETH, J. O. Holloszy, AND O. H. LoWRY. Effects of detraining on enzymes of energy metabolism in individual human muscle fibers. Am. J. Physiol. 244 (Cell Physiol. 13): C276-C287, 1983.

9. Christensen, E. H., AND O. Hansen. Arbeitsfähigkeit und ehrnährung. Skand. Arch. Physiol. 81: 160-171, 1939.

10. Constantin-Teodosiu, D., J. Carlin, G. Cederblad, R. C. HARRIS, AND E. HULTMAN. Acetyl group accumulation and pyruvate dehydrogenase activity in human muscle during incremental exercise. Acta Physiol. Scand. 143: 367-372, 1991.

11. Cooperstein, S. J., A. Lazarow, and N. J. Kurfess. A microspectrophotometric method for the determination of succinic dehydrogenase. J. Biol. Chem. 186: 129-139, 1950.

12. Costill, D. L., W. J. Fink, M. Hargreaves, D. S. King, R. THOMAS, AND R. FIELDING. Metabolic characteristics of skeletal muscle during detraining from competitive swimming. Med. Sci. Sports Exercise 17: 339-343, 1985.

13. Davies, K. J. A., L. Packer, And G. A. Brooks. Biochemical adaptation of mitochondria, muscle, and whole-animal respiration to endurance training. Arch. Biochem. Biophys. 209: 539-554, 1981.

14. Elander, A., M. SJöström, F. Lundgren, T. SchERSTÉn, AND A.-C. BYLUND-FELLENIUS. Biochemical and morphometric properties of mitochondrial populations in human muscle fibers. Clin. Sci. Lond. 69: 153-164, 1985.

15. Gollnick, P. D., AND B. SAltin. Significance of skeletal muscle oxidative enzyme enhancement with endurance training. Clin. Physiol. 2: 1-12, 1982.

16. HenRIKsson, J. Human Skeletal Muscle Adaptation to Physical Activity (PhD thesis). Stockholm: Karolinska Institute, 1976.

17. HENRIKSSON, J. Training induced adaptation of skeletal muscle and metabolism during submaximal exercise. J. Physiol. Lond. 270: 661-675, 1977.

18. HeNRIKSSON, J., AND J. S. REITMAN. Time course of changes in human skeletal muscle succinate dehydrogenase and cytochrome oxidase activities and maximal oxygen uptake with physical activity and inactivity. Acta Physiol. Scand. 99: 91-97, 1977.

19. Hermansen, L., E. Hultman, AND B. Saltin. Muscle glycogen during prolonged severe exercise. Acta Physiol. Scand. 71: 129-139, 1967.

20. Holloszy, J. O. Biochemical adaptations in muscle. Effects of exercise on mitochondrial oxygen uptake and respiratory enzyme activity in skeletal muscle. J. Biol. Chem. 242: 2278-2282, 1967.

21. Holloszy, J. O. Biochemical adaptations to exercise: aerobic metabolism. Exercise Sport Sci. Rev. 1: 45-71, 1973.

22. Hoppeler, H., H. Howald, K. Conley, S. L. LindstedT, H. ClaAssen, P. Vock, AND E. R. Weibel. Endurance training in humans: aerobic capacity and structure of skeletal muscle. J. Appl. Physiol. 59: 320-327, 1985.

23. Klausen, K., L. B. Andersen, and I. Pelle. Adaptive changes in work capacity, skeletal muscle capillarization and enzyme levels during training and detraining. Acta Physiol. Scand. 113: 9-16, 1981.

24. Lowry, O. H., N. J. Rosebrough, A. L. FARR, AND R. J. RANDALL. Protein measurement with the Folin phenol reagent. J. Biol. Chem. 193: 265-275, 1951.

25. Molé, P. A., L. B. OsCAI, AND J. O. Holloszy. Adaptation of muscle to exercise. Increase in levels of palmitoyl CoA synthetase, carnitine palmityltransferase, and palmityl CoA dehydrogenase, and 
in the capacity to oxidize fatty acids. $J$. Clin. Invest. 50: 2323-2330, 1971.

26. OPIE, L., AND E. NEwSHOLME. The activities of fructose 1,6-diphosphatase, phosphofructokinase and phosphoenolpyruvate carboxykinase in white muscle and red muscle. Biochem. J. 103: 391399, 1967.

27. SALTIN, B., AND P. D. GollNick. Skeletal muscle adaptability: significance for metabolism and performance. In: Handbook of Physiology. Skeletal Muscle. Bethesda, MD: Am. Physiol. Soc., 1983, sect. 10, chapt. 19 , p. 555-631.

28. SchanTZ, P. G. Plasticity of human skeletal muscle with special reference to effects of physical training on enzyme levels of the NADH shuttles and phenotypic expression of slow and fast isoforms of myofibrillar proteins. Acta Physiol. Scand. 128, Suppl. 558: $1-62,1986$.

29. SChanTZ, P., J. HeNRIKSSON, AND E. JANSSON. Adaptation of human skeletal muscle to endurance training of long duration. Clin. Physiol. 3: 141-151, 1983.

30. Schantz, P. G., B. SJöBERG, AND J. Svedenhag. Malate-aspartate and alpha-glycerophosphate shuttle enzyme levels in human skeletal muscle: methodological considerations and effect of endurance training. Acta Physiol. Scand. 128: 397-407, 1986.
31. ScHMIDT, E. Glutamate dehydrogenase. In: Methods of Enzymatic Analysis (2nd ed.), edited by H. U. Bergmeyer. New York: Academic, 1974, p. 650-656.

32. Sottocasa, G. L., B. Kuylenstierna, L. Ernster, and A. BERGSTRAND. An electron-transport system associated with the outer membrane of liver mitochondria. A biochemical and morphological study. J. Cell Biol. 32: 415-438, 1967.

33. STRÖM, G. The influence of anoxia on lactate utilization in man after prolonged muscular work. Acta Physiol. Scand. 17: 440-451, 1949.

34. Tottmar, S., H. Pettersson, AND K.-H. Kiessling. The subcellular distribution and properties of aldehyde dehydrogenases in rat liver. Biochem. J. 135: 577-586, 1973.

35. Ward, G. R., J. D. MacDougall, J. R. SutTon, C. J. Toews, AND N. L. JONES. Activation of human muscle pyruvate dehydrogenase with activity and immobilization. Clin. Sci. Lond. 70: 207-210, 1986.

36. WIBOM, R., AND E. HULTMAN. ATP production rate in mitochondria isolated from microsamples of human muscle. Am. J. Physiol. 259 (Endocrinol. Metab. 22): E204-E209, 1990.

37. Wibom, R., A. Lundin, AND E. Hultman. A sensitive method for measuring ATP-formation in rat muscle mitochondria. Scand. $J$. Clin. Lab. Invest. 50: 143-152, 1990.

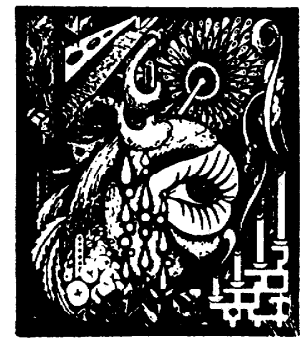

